\section{Vladimir A. Kodnyanko \\ Professor \\ Polytechnical Institute Siberian Federal University \\ Russia}

\section{Andrey S. Kurzakov}

AssociateProfessor

Polytechnical Institute Siberian Federal University

\title{
Static Characteristics of a Hydrostatic Thrust Bearing with a Membrane Displacement Compensator
}

The article discusses the design and also presents a mathematical model and method for calculation of static characteristics of a hydrostatic thrust bearing with a membrane-type displacement compensator. Formulae for calculation of compliance and load characteristics of the bearing are also presented, as well as deformation and compliance of the membrane at which zero compliance of the bearing is guaranteed.

Key words: hydrostatic bearing, compliance, negative compliance, zero compliance, load characteristics, displacement compensator, membrane.

\section{INTRODUCTION}

Units with non-contact hydrostatic slide bearings are widely used in metal-cutting machines for precision and high-speed machining, micro-machining, in heavy and unique machine tools. Hydrostatic bearings provide precision and cleanliness of processing, load characteristics, vibration resistance, and high durability of ultra-hard cutting tools that cannot be provided by other types of sliding and rolling bearings [1-3].

The main prospects for further research and development in this area of science and technology are in the area of creation and complex use of spindle assemblies and guides with adaptive hydrostatic bearings, which have regulators of active lubricant injection, in metal-cutting machines. Further improvement of technical solutions, development of theory and methods for optimal design of spindle assemblies and guides with adaptive hydrostatic bearings is an urgent scientific and technical problem of mechanical engineering, the solution of which can significantly increase the accuracy and productivity of machining with metalcutting equipment $[4,5]$.

Modern hydrostatic bearings should have a compact and technologically advanced design with elastically built-in, elastomeric, floating and other regulators of performance characteristics, surpass their counterparts in accuracy, load-bearing capacity, compliance and other important performance characteristics.

Mechanical engineering, and particularly heavy machine-tool construction, needs such hydrostatic bearings with active displacement compensators that have the ability to provide low positive, as well as zero and negative compliance $[6,7]$. In comparison with bearings with active flow rate compensation, such structures are distinguished by significantly lower energy consumption and the ability to compensate for movements with amplitudesat which other hydrostatic bearings would be obviously inoperative [6]. In addition, bearings with displacement compensation have more stable load characteristics and significantly better

Received: October 2020, Accepted: June 2021

Correspondence to: Dr Vladimir Kodnyanko

Polytechnical Institute, Siberian Federal University,

Kirensky Str. 28, 660074, Krasnoyarsk, Russia

E-mail: kowlad@rambler.ru

doi:10.5937/fme2103764K

(C) Faculty of Mechanical Engineering, Belgrade. All rights reserved dynamics when operating in low compliance modes [8].

The role of active displacement compensators can be performed by elastic rings or membranes, the use of which is preferable due to longer retention of stable elastic characteristics $[9,10]$.

Shown in Figure 1, the bearing structure contains a fixed 1 and a movable 2 disks, which are connected to each other by an annular membrane 3 , which together with Disk 2 acts as a movement compensator. Elements $1-3$ form the base of the bearing. The suspended part is Disk 4, which takes an external load $f$ and is separated from the base of the bearing by a lubricating gap of thickness $h$. The bearing is powered by the inlet throttle 5 , which is supplied with lubricant under pressure $p_{s}$. At the outlet of the throttle, the lubricant enters the flow cavity 6 under pressure $p_{k}$ and then, having overcome the carrier layer, flows out of the bearing.

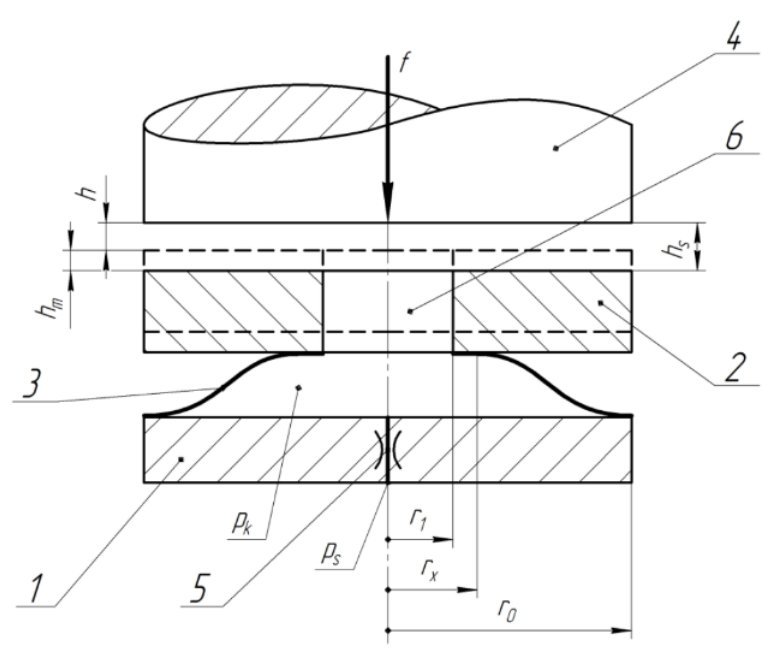

Figure 1. Hydrostatic thrust bearing structure with a membrane displacement compensator

A decrease in compliance occurs under effect of hydrostatic forces due to the displacement of Disk 2 in the direction opposite to the direction of force $f$. By varying the compliance coefficient $k_{m}$ of the membrane 3 , in particular its thickness, it is possible to achieve the required value of its deformation $h_{m}$ so that the total displacement $h_{s}=h_{m}+h$ of the suspended Disk 4 relative to Disk 1 will have a lower compliance in comparison with the usual bearing $k=-\partial h_{s} / \partial f$, including zero and negative compliance. 


\section{MATHEMATICAL MODELLING AND CALCULATION METHODS}

Functions of pressure distribution $p(r)$ in the lubricant gap and membrane deflection $u(r)$ under the action of hydrostatic forces satisfy the boundary problems

$$
\begin{aligned}
& \left\{\begin{array}{l}
\frac{d}{d r}\left(h^{3} r \frac{d p}{d r}\right)=0, \\
p\left(r_{1}\right)=p_{k}, p\left(r_{0}\right)=0,
\end{array}\right. \\
& \left\{\begin{array}{l}
\frac{1}{r} \frac{d}{d r}\left\{r \frac{d}{d r}\left[\frac{1}{r} \frac{d}{d r}\left(r \frac{d u}{d r}\right)\right]\right\}=\frac{12\left(1-v^{2}\right) g}{E \delta^{3}}, \\
u\left(r_{0}\right)=0, \frac{d u}{d r}\left(r_{1}\right)=0, \frac{d u}{d r}\left(r_{0}\right)=0, \frac{d^{2} u}{d r^{2}}\left(r_{1}\right)=0,
\end{array}\right.
\end{aligned}
$$

where $r_{0}, r_{1}$ are the outer and inner radii of the membrane and the movable disk respectively, $g(r)$ is the load on the membrane, $\delta$ is the membrane thickness, $v$ is the Poisson's ratio, $E$ is the elastic modulus of the membrane material [11].

The bearing capacity $w$ is the sum of integral hydrostatic forces

$$
w_{1}=2 \pi \int_{0}^{\eta} r p d r, w_{2}=2 \pi \int_{\eta_{1}}^{r_{0}} r p d r
$$

where $w_{1}$ is the hydrostatic force applied to the suspended Part 4 from the side of the central circle of radius $r_{1} ; w_{2}$ is the hydrostatic force applied simultaneously to the annular periphery of the suspended Part 4 , on the movable Disk 2, and the membrane.

The study of static characteristics of the bearing is carried out in a dimensionless form. The scale for the main variables is as follows: the outer radius $r_{0}$ for linear dimensions, $p_{s}$ for pressures, $\pi r_{0}^{2} p_{s}$ for forces, $\mathrm{h}_{0}{ }^{3} p_{s} / 12 \mu$ for volumetric flow rates of the operating fluid flow, $h_{0}$ for the lubricating gap and small displacements, where $h_{0}$ is the thickness of the gap $h$ in the calculated point, $\mu$ is the viscosity of the lubricant.

Below, dimensionless variables are designated in capital letters.

Solution to problem (1) for dimensionless pressure function would be:

$$
P(R)=\left\{\begin{array}{l}
P_{k}, R \in\left[0, R_{1}\right], \\
P_{k} \frac{\ln R}{\ln R_{1}}, R \in\left[R_{1}, 1\right],
\end{array}\right.
$$

where $R_{1}$ is dimensionless inner radius of Disk 2 and the membrane, $P_{k}$ is dimensionless pressure at the outlet of the throttle and at the entrance to the lubricating gap.

Taking into account (3) - (5), formulas were obtained for dimensionless hydrostatic forces and load capacity of the bearing

$$
W_{1}=A_{W 1} P_{k}, W_{2}=A_{W 2} P_{k}, W=W_{1}+W_{2}=A_{W} P_{k},
$$

where

$$
A_{W 1}=\frac{R_{1}^{2}-1}{2 \ln R_{1}}-R_{1}^{2}, A_{W 2}=R_{1}^{2}, A_{W}=A_{W 1}+A_{W 2} .
$$

Dimensionless flow rates through the bearing and the throttle are determined by the formulas

$$
Q_{h}=-\frac{H^{3} P_{k}}{\ln R_{1}}, Q_{d}=A_{d}\left(1-P_{k}\right),
$$

where $A_{d}$ is the throttle parameter.

When solving boundary problem (2), it is convenient to represent the main differential equation and boundary conditions in the following form:

$$
\left\{\begin{array}{l}
R^{2} \frac{d^{2} \Phi}{d r^{2}}+R \frac{d \Phi}{d r}-\Phi=-B K_{m} R^{2} I(R), \\
\frac{d U}{d r}=-\Phi \\
U(1)=0, \Phi\left(R_{1}\right)=0, \Phi(1)=0
\end{array}\right.
$$

where $U(R), \Phi(R)$ are dimensionless functions of the deflection and inclination angle of the membrane,

$$
\begin{aligned}
& B=\frac{r_{0}}{h_{0}}, \\
& I(R)=\int_{R_{1}}^{R} R G(R) d R, \\
& K_{m}=12\left(1-v^{2}\right) \frac{p_{s}}{E}\left(\frac{r_{0}}{\delta}\right)^{3}
\end{aligned}
$$

are coefficient of similarity, dimensionless distributed load on the membrane, and the coefficient of its cylindrical compliance.

The load function $I(R)$ is determined by pressure $P_{k}$ acting on the membrane from the side of Cavity 6 and by the component of the bearing capacity $W_{2}$, which creates a uniform load onto the membrane along the ring of $R \in\left[R_{1}, R_{x}\right]$ of membrane's contact with the movable Disk 2 (Fig. 2)

$$
I(R)=\left\{\begin{array}{l}
\frac{1}{2}\left(P_{k}-\frac{W_{2}}{R_{x}^{2}-R_{1}^{2}}\right)\left(R^{2}-R_{1}^{2}\right), R \in\left[R_{1}, R_{x}\right], \\
\frac{1}{2}\left[P_{k}\left(R^{2}-R_{1}^{2}\right)-W_{2}\right], R \in\left[R_{x}, 1\right] .
\end{array}\right.
$$

The solution of the boundary problem (10) for functions $\Phi$ and $U$ was obtained by numerical grid sweeping method [12]. For this, segment $R \in\left[R_{1}, 1\right]$ was divided into $n$ equal parts, the problem was reduced to an algebraic form, and a system of linear equations was solved

$$
\left\{\begin{array}{l}
R_{i}\left(2 R_{i}+\tau\right) \Phi_{i+1}-2\left(2 R_{i}^{2}+\tau^{2}\right) \Phi_{i}+ \\
+R_{i}\left(2 R_{i}-\tau\right) \Phi_{i-1}=-2 B K_{m} \tau^{2} R_{i}^{2} I\left(R_{i}\right) \\
\Phi_{0}=0, \Phi_{n}=0, i=1,2, \ldots, n-1 \\
U_{i}=U_{i+1}+\Phi_{i} \\
U_{n}=0, \quad i=n-1, n-2, \ldots, 0
\end{array}\right.
$$


where $R_{i}=1+i \tau, \Phi_{i}=\Phi\left(R_{i}\right), U_{i}=U\left(R_{i}\right), \tau=\left(1-R_{1}\right) / n$ is the grid step.

The deflection of the membrane $U_{0}=U(0)$ determines the axial displacement $H_{m}$ of the movable Disk 2 .

The design conditions of the bearing were found from condition $h=h_{0}$, i.e., at $H=1$ and thedefined value of the throttle resistance adjustment factor, which in the design mode is equal to pressure $P_{k}$. Having comparedflow rates (8) and (9) in this mode, we found the throttle parameter

$$
A_{d}=\frac{\chi}{(\chi-1) \ln R_{1}} .
$$

In the calculations, the following parameters were used as input parameters: $\chi, R_{1}, K_{m}, P_{k}, B$. Taking into account the fact that the thickness of the bearing gap is three orders of magnitude smaller than its characteristic dimensions, it has been assumed that $B=1000$.

\section{MEMBRANE DEFLECTION CHARACTERISTICS}

Calculations have shown that the deflection function $U(R)$ is proportional to parameters $P_{k}, K_{m}$ and therefore, can be represented as

$$
U(R)=K_{m} P_{k} V(R) .
$$

It has been found that if the deflection model takes into account only the edge contact of the membrane with the movable disk $\left(R_{x} \approx R_{1}\right)$, then the function $V(R)$ calculated when solving problem (11) turns out to be convex (Fig. 2, curve 1), which does not correspond to the operating conditions of the bearing, since for design reasons this curve should be monotonic. In the calculations, the convex section is eliminated by increasing radius $\mathrm{Rx}$, which means the area of surface contact between the membrane and the diskto which the hydrostatic force $W_{2}$ is applied. This causes a decrease in the specific load (pressure) on the membrane from the side of the movable ring 2, which should contribute to increase in membrane deflection.

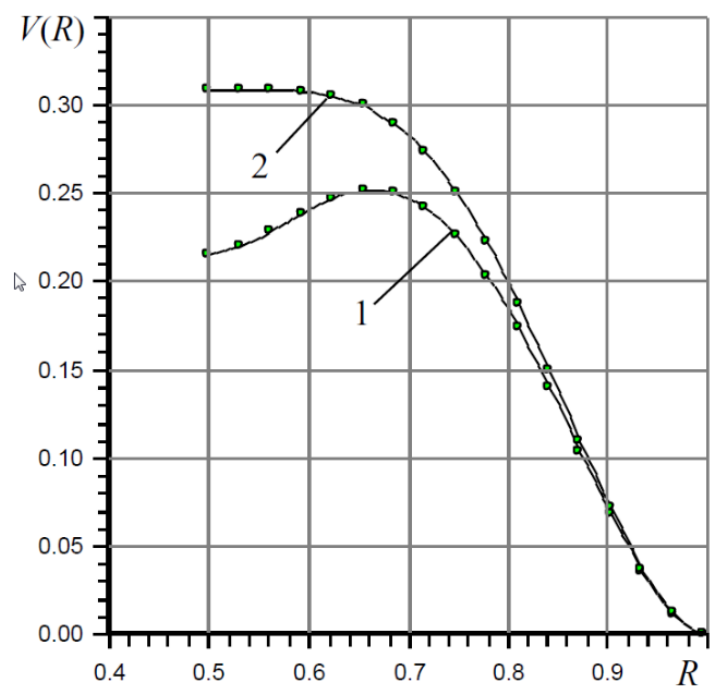

Figure 2. Curves of the deflection function at edge (1) and ring (2) contacts of the membrane with the disc, $R_{1}=0.5$

The minimum radius $R_{x}$ of the membraneto Disk 2 contact has been found among monotonic functions
$V(R)$ corresponding to the condition $d V / d R \leq 0$. In Fig. 2 , this corresponds to curve 2, for which $R_{x}=0.638$.

Figure 3 shows the dependences $V(R)$ at different values of $R_{1}$. As can be seen from the graphs, these relations significantly depend on this radius.

In the range $R_{1} \in[0.35,0.65]$, the value $H_{R}=V\left(R_{1}\right)$ with an error of no more than 0.01 can be calculated using the approximate formula

$$
H_{R}=16.19 R_{1}-26.85 \sqrt{R_{1}}+11.2 .
$$

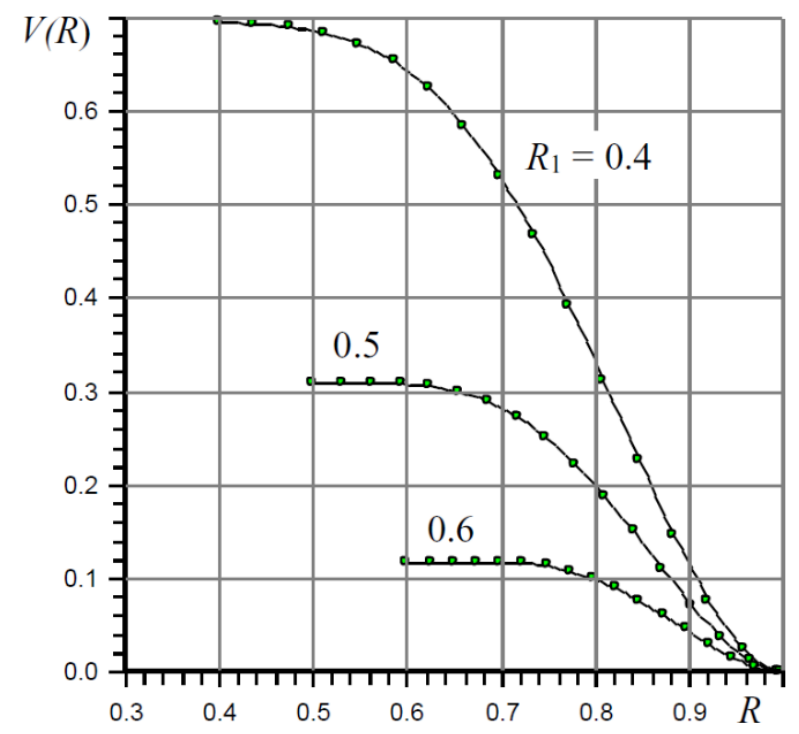

Figure 3. Curves of the dependence of the membrane deflection for different values of the radius $R_{1}$

The resulting dependence enables to obtain a simple model for calculation of static characteristics of a bearing in analytical form and obtain formulae for the characteristic modes of its compliance.

\section{BEARING CHARACTERISTICS}

Bearing compliance is determined by the formula $K=-$ $d H_{s} / d W$, where $H_{s}=H+H_{m}, H_{m}=K_{m} P_{k} H_{R}$.

Because the

$$
H_{s}=\sqrt[3]{\frac{\chi\left(1-P_{k}\right)}{(1-\chi) P_{k}}}+K_{m} P_{k} H_{R},
$$

then after differentiating (13) with respect to $P_{k}$, taking into account (6), we obtain a formula to calculate the bearing compliance

$$
\begin{aligned}
& K=-\frac{d H_{s}}{d P_{k}} \frac{d P_{k}}{d W}= \\
& =\frac{1}{A_{w}}\left[\frac{1}{3 P_{k}^{2}} \sqrt[3]{\frac{\chi P_{k}^{2}}{(1-\chi)\left(1-P_{k}\right)^{2}}}-K_{m} H_{R}\right],
\end{aligned}
$$

where according to (6) $P_{k}=W / A_{w}$.

Substituting $\chi=P_{k}$, in (14), we find the formula to determine the bearing compliance in the design loading mode

$$
K_{0}=\frac{1}{A_{w}}\left[\frac{1}{3 \chi(1-\chi)}-K_{m} H_{R}\right] .
$$


Formula (15) allows us to find the value of the cylindrical compliance of the membrane at which the bearing in the design mode will have zero compliance $K_{0}=0$

$$
K_{m 0}=\frac{1}{3 \chi(1-\chi) H_{R}} .
$$

So, at $\chi=0.5$ and $R_{1}=0.5$, the bearing has zero compliance at $K_{m 0}=4.55$.

Figure 4 shows the dependences of the bearing compliance $K_{0}$ in the design loading mode on the throttle setting parameter $\chi$.

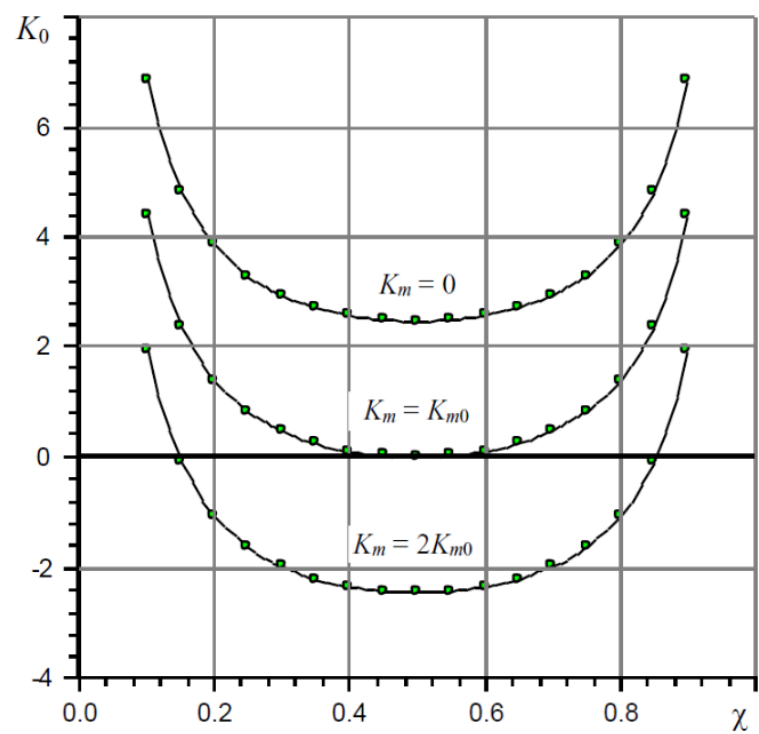

Figure: 4. Curves of dependence of compliance $K_{0}$ on parameter $X$ at different values of the membrane compliance $K_{m}$

With increase in compliance $K_{m}$, the bearing compliance $K_{0}$ decreases and at $K_{m}=K_{m 0}$ and at a certain value of $\chi$ the bearing reaches zero compliance $\left(K_{0}=\right.$ $0)$.With a further increase in $K_{m}$ and negative compliance $\left(K_{0}<0\right)$ curves $K_{0}(\chi)$ become extremal. The minimum of this dependence occurs at $\partial K_{0} / \partial \chi=0$.

Differentiating (15) and solving this equation, we find the optimal value of the coefficient $\chi=0.5$. Graphs in Fig. 4 confirm this result.

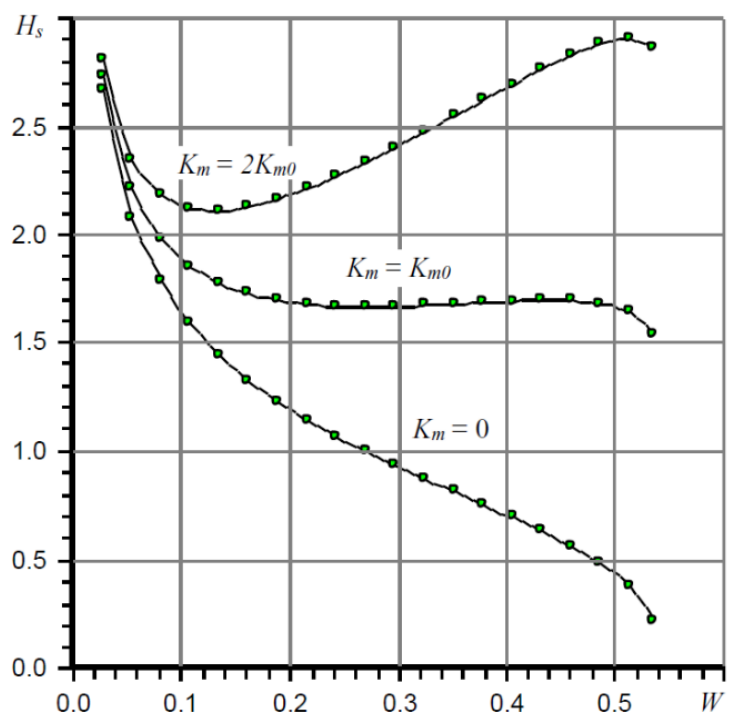

Figure 5. Bearing load characteristics, $X=0.65, R_{1}=0.5$
Figure 5 shows the load characteristics $H_{s}(W)$ of the bearing for the modes of positive, zero and negative compliance. The calculation of the characteristics was carried out in a parametric form according to formulas (13), (6), (7)with pressure $P_{k} \in(0,1)$ as parameter.

It can be seen that in active displacement compensation modes the characteristics retain a fairly wide range of stable compliance in the region of moderate and large loads up to the maximum ones.

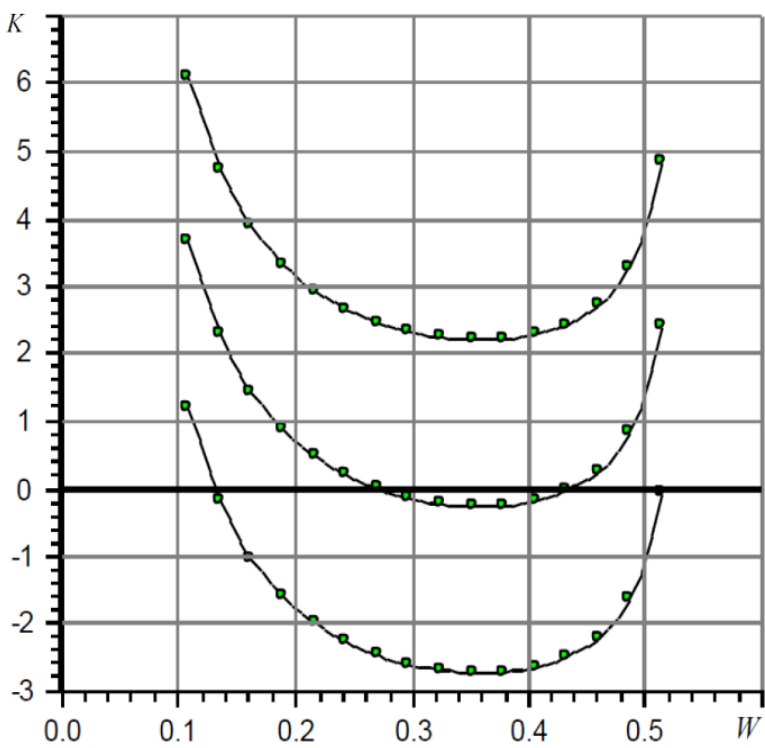

Figure 6. Bearing compliance $K$ in the load range $W$, $\mathrm{X}=0.5, R_{1}=0.5$

Curves in Figure 6 give more details about the bearing compliance in the range of its loads.

The graphs show that the minimum of the compliance function $K(W)$ corresponds to the load $W_{k}>W_{0}$, where $W_{0}$ is the load corresponding to the design clearance $H=1$. For these curves, $W_{0}=0.271$.

The minimum value of compliance and the corresponding load can be found from equation $\partial K / \partial W=0$. Having performed differentiation (14) and solving the corresponding equation, we obtain optimal $P_{k}=\frac{2}{3}, W_{k}=\frac{2}{3} A_{w .}$ For Figure 6 this corresponds to $W_{k}=$ 0.361 .

\section{CONCLUSION}

The results obtained allow us to conclude that open hydrostatic thrust bearing with membrane displacement compensators have a number of important properties that significantly expand the area of efficient application of active hydrostatic bearings in metal-cutting machines in order to improve the processing quality. In particular, they make it possible to compensate for large deformations of the elastic system of machine tools by using the negative compliance mode, which is difficult or impossible to achieve using conventional hydrostatic bearings or bearings with compensation of the working fluid flow rate.

The discovered proportional relation between the membrane deflection and the product of its cylindrical compliance and the applied pressure has enabled us to 
build a simple engineering model based on elastic properties of the membrane. This model is a basis to develop an analytical method for calculation of

\section{ACKNOWLEDGEMENT}

The work has been carried out within the framework of the scientific research budget themes «Methods of modelling and optimization of quality control information systems on the basis of intellectual technologies») at the Department of Standardization, Metrology and Quality Management and Department of Design and Technological Support of Machine-building Industries of the Polytechnic Institute of the Siberian Federal University.

\section{REFERENCES}

[1] SKF hydrostatic bearings, Mach. and Prod. Eng., 1973, March, 21, pp. 381-384.

[2] Howarht, R. B., Newton, M. J. Inivestigation of the effects of tilt and sliding on the performance of hydrostatic thrust bearings, Externall pressurized bearings, London, 1972, pp. 146-156.

[3] Jayachandra, P. T., Ganosan, N. Behaviour of multirecess plane-hydrostatic thrust bearings under conditions of tilt and rotation, Wear, 1983, 92, No 2. pp. 243-251.

[4] Mizumoto, H. A., Kubo, M., Makimoto, Y., Yoshimochi S., Okamura, S., Matsubara T. Hydrostatically Controlled Restrictor for an Infinite Stiffness Hydrostatic Journal Bearing, Bull. Japan Soc. ofPrec. Engg., 1987, 21, No 1, pp. 49-54;

[5] Popovic, M. R., Tanovic, L., Ehmann, K. E.: Cutting Forces Prediction: the Experimental Identification of Orthogonal Cutting Coefficients, Trans. FME Transactions, 2017, Vol. 45, No. 4, pp. 459-467.

[6] Kodnyanko, V. A. Characteristics of a gas-static thrust bearing with an active displacement controller, STIN, 2005, No. 9,pp. 32-34. (in Russian).

[7] Pikalov, Ya. Yu., Shatokhin, S. N., Demin, V. G. Adaptive hydrostatic spindle bearings with a floating regulator, STIN. 2006, No. 50,pp. 18-22. (in Russian).

[8] Shatokhin, S. N., Kodnyanko, V. A. Load and flow characteristics of an axial gas-static support with active compensation of gas consumption, Mashinovedenie,1980, No. 6,pp. 32-36. (in Russian).

[9] Kodnyanko, V. A., Pikalov, Yu., A., Shatokhin, S. N. Study of the characteristics of a gasostatic support with active flow rate compensation, Bulletin of mechanical engineering, No. 4, 1979, pp. 9-12. (in Russian).

[10] Kodnyanko, V. A., Shatokhin, S. N. Load and flow characteristics of an axial gas-static support with parameters and static operating characteristics of the bearing.

active compensation of gas flow, Mashinovedenie, No. 6, 1980,pp. 33-35. (in Russian).

[11] Weinberg, D.V., Weinberg, E. D. Calculation of plates, Kiev, Budivelnik, 1970, P. 436. (in Russian).

[12] Demidovich, B. P., Maron, I. A., Shuvalova, E. Z. Numerical methods of analysis, Lan, 2010, P. 298. (in Russian).

\section{NOMENCLATURE}

$H, h, \quad$ dimensionless thickness, current thicknessof

$h_{0}$, the gap and its thickness in the calculated point,

$H_{m} \quad$ dimensionless membrane deflection,

$E \quad$ elastic modulus of the membrane material

$K$ dimensionless bearing compliance

$K_{m} \quad$ dimensionless membrane compliance

$P(R) \quad$ dimensionless pressure in the carrier gap

$P_{k} \quad$ dimensionless pressure at the outlet of the throttle

$p_{s} \quad$ supply pressure

$Q_{h} \quad$ dimensionless flow rate through the gap

$Q_{d} \quad$ dimensionless flow rate through the throttle the outer and inner radii

$r_{0}, r_{1} \quad$ dimensionless inner radius

$R_{1} \quad$ dimensionless functions of the membrane

$U(R) \quad$ deflection

dimensionless bearing capacity

$W \quad$ dimensionless functions of the membrane

$\Phi(R) \quad$ inclination angle membrane thickness

$\delta \quad$ coefficient of dynamic viscosity of lubricant

$\mu \quad$ normalized adjustment coefficient of the external throttle

\section{СТАТИЧКЕ КАРАКТЕРИСТИКЕ ХИДРОСТАТИЧКОГ АКСИЈАЛНОГ ЛЕЖАЈА СА МЕМБРАНСКИМ КОМПЕНЗАТОРОМ ПОМЕРАЊА}

\section{В.А. Кодњанко, А.С. Курзаков}

Рад се бави дизајном и приказом математичког модела и методе израчунавања статичких карактеристика хидростатичког аксијалног лежаја са мембранским компензатором померања. Дате су и формуле за израчунавање карактеристика усаглашености и оптерећења, као и сигурна деформација и усаглашеност мембране при нултој усаглашености лежаја. 